\title{
Endoscopic Ultrasound-Guided Perirectal Abscess Drainage without Drainage Catheter: A Case Series
}

\author{
Eun Kwang Choi ${ }^{1}$, Ji Hyun Kim², Seung Uk Jeong ${ }^{1}$, Soo-Young Na ${ }^{1}$, Sun-Jin Boo ${ }^{1}$, Heung Up Kim and Byung-Cheol Song ${ }^{1}$ \\ ${ }^{1}$ Department of Internal Medicine, Jeju National University School of Medicine, Jeju, ${ }^{2}$ Department of Internal Medicine, Busan Paik Hospital, \\ Inje University College of Medicine, Busan, Korea
}

A perirectal abscess is a relatively common disease entity that occurs as a postsurgical complication or as a result of various medical conditions. Endoscopic ultrasound (EUS)-guided drainage was recently described as a promising alternative treatment. Previous reports have recommended placement of a drainage catheter through the anus for irrigation, which is inconvenient to the patient and carries a risk of accidental dislodgement. We report four cases of perirectal abscess that were successfully treated with only one or two $7 \mathrm{~F}$ double pigtail plastic stent placements and without a drainage catheter for irrigation. Clin Endosc 2017;50:297-300

Key Words: Endosonography; Perirectal abscess; Drainage

\section{INTRODUCTION}

Pelvic abscesses are commonly located close to the rectum or sigmoid colon. They occur as a postoperative complication or as a result of various medical conditions. ${ }^{1}$ Percutaneous drainage under ultrasound (US) or computed tomography (CT) guidance has been the standard therapy for pelvic abscesses. However, because of the unique complexity of the structures surrounding the abscess, there are cases in which percutaneous drainage is not possible. Further, these procedures can cause intra- or post-procedural pain and discomfort because of indwelling catheters. Endoscopic ultrasound (EUS)-guided drainage of pelvic abscesses was recently described as a treatment option and is a feasible procedure for transrectal and transsigmoid drainage of perirectal or pelvic abscesses. $^{2,3}$ There have been concerns that transrectal stents

Received: August 23, 2016 Revised: January 30, 2017

Accepted: February 11, 2017

Correspondence: Eun Kwang Choi

Department of Internal Medicine, Jeju National University School of Medicine, 15 Aran 13-gil, Jeju 63241, Korea

Tel: +82-64-754-8162, Fax: +82-64-717-1131, E-mail: cek@jejunu.ac.kr

(cc) This is an Open Access article distributed under the terms of the Creative Commons Attribution Non-Commercial License (http://creativecommons.org/ licenses/by-nc/3.0) which permits unrestricted non-commercial use, distribution, and reproduction in any medium, provided the original work is properly cited. can easily clog because of feces or pus. ${ }^{3,4}$ To overcome this, some studies recommend a drainage catheter for flushing the abscess. ${ }^{3,4}$ However, the catheter can be inconvenient for patients with restricted mobility and poses a risk for accidental dislodgement. ${ }^{5}$ Here, we report four cases of perirectal abscess that were successfully treated with only one or two $7 \mathrm{~F}$ double pigtail stents without a drainage catheter for irrigation.

\section{CASE REPORT}

This is a retrospective analysis of patients who underwent EUS-guided drainage of perirectal abscesses between July 2012 and December 2015, at two academic centers. This study was approved by the institutional review board of both hospitals. Informed consent was obtained from all patients before the procedure. All procedures were performed by a single experienced therapeutic endoscopist in each center. The rectum and distal colon were prepared on the day of the procedure by administration of either a soapsuds or Yal (Trommsdorff GmbH \& Co. KG, Alsdorf, Germany) enema. All patients were administered antibiotics before the intervention. Patients were also instructed to void urine before the procedure. All procedures were performed with the patients under conscious sedation with a combination of intravenous meperidine, mid- 
Table 1. The Clinical Features and Outcomes in 4 Patients with EUS-Guided Drainage of Perirectal Abscess

\begin{tabular}{|c|c|c|c|c|c|c|c|c|c|c|c|}
\hline & Age & Sex & Etiology & $\begin{array}{l}\text { Abscess } \\
\text { size }(\mathbf{m m})\end{array}$ & $\begin{array}{l}\text { Dilation } \\
\text { method }\end{array}$ & $\begin{array}{c}\text { Stent } \\
\text { number }\end{array}$ & $\begin{array}{l}\text { Stent } \\
\text { type }\end{array}$ & $\begin{array}{c}\text { Stent } \\
\text { duration } \\
\text { (days) }\end{array}$ & Complications & $\begin{array}{c}\text { Stent } \\
\text { migration }\end{array}$ & Outcome \\
\hline Case 1 & 47 & $\mathrm{M}$ & $\begin{array}{l}\text { Lap. } \\
\text { Chole }\end{array}$ & $83 \times 60$ & $\begin{array}{l}\text { Graded } \\
\text { dilation }\end{array}$ & 2 & $\begin{array}{l}7 \mathrm{~F} 4 \mathrm{~cm} \\
7 \mathrm{~F} 5 \mathrm{~cm}\end{array}$ & 14 & None & No & $\begin{array}{l}\text { Complete } \\
\text { resolution }\end{array}$ \\
\hline Case 2 & 48 & $\mathrm{~F}$ & RT & $55 \times 32$ & $\begin{array}{l}\text { Graded } \\
\text { dilation }\end{array}$ & 2 & $\begin{array}{l}7 \mathrm{~F} 4 \mathrm{~cm} \\
7 \mathrm{~F} 4 \mathrm{~cm}\end{array}$ & 7 & None & No & $\begin{array}{l}\text { Complete } \\
\text { resolution }\end{array}$ \\
\hline Case 3 & 21 & $\mathrm{M}$ & $\begin{array}{l}\text { Lap. } \\
\text { Appe }\end{array}$ & $59 \times 42$ & Cystotome & 2 & $\begin{array}{l}7 \mathrm{~F} 8 \mathrm{~cm} \\
7 \mathrm{~F} 8 \mathrm{~cm}\end{array}$ & 7 & None & No & $\begin{array}{l}\text { Complete } \\
\text { resolution }\end{array}$ \\
\hline Case 4 & 17 & F & $\begin{array}{l}\text { Lap. } \\
\text { Appe }\end{array}$ & $40 \times 32$ & Cystotome & 1 & $7 \mathrm{~F} 6 \mathrm{~cm}$ & 9 & None & No & $\begin{array}{l}\text { Complete } \\
\text { resolution }\end{array}$ \\
\hline
\end{tabular}

EUS, endoscopic ultrasound; Lap, laparoscopic; Chole, cholecystectomy; RT, radiation therapy; Appe, appendectomy.

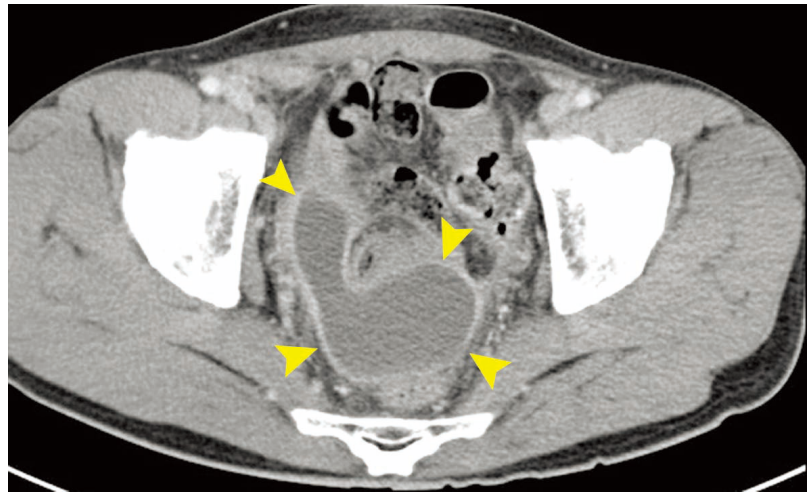

Fig. 1. Initial computed tomography (CT) image showing an $83 \times 60 \mathrm{~mm}$ abscess cavity (arrow heads) with an enhancing wall.

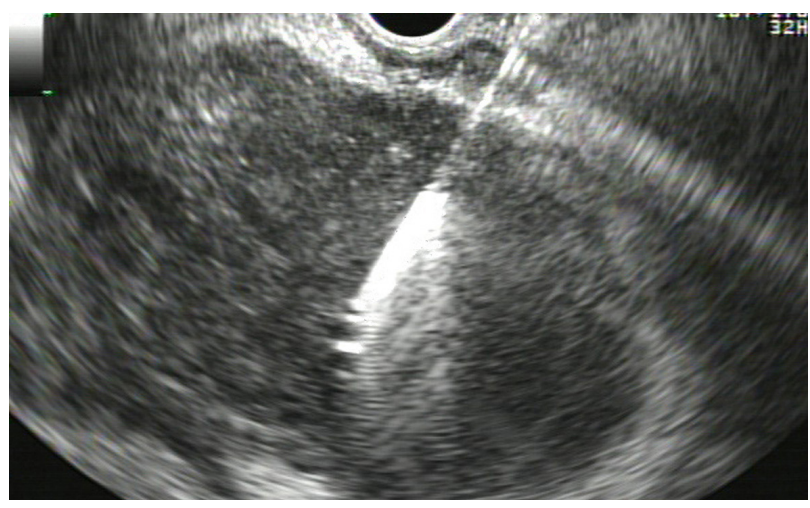

Fig. 2. Curved linear-array endoscopic ultrasound (EUS) image showing the 19-gauge needle within the abscess cavity.

azolam, and propofol.

All four patients underwent EUS-guided drainage of perirectal abscesses (Table 1). The median patient age was 34 years (range, 17-48), and two of the patients were male, while the remaining two were female. The cause of perirectal abscess was postsurgical complication in three patients and proctitis after radiation therapy (RT) for cervical cancer in one patient. All patients presented with lower abdominal pain and fever.
Initial laboratory tests showed elevated white blood cell counts and C-reactive protein levels in all patients. A CT scan was performed before the procedure in all patients. The median abscess size was $57 \times 37 \mathrm{~mm}$ (range, $40 \times 32 \mathrm{~mm}$ to $83 \times 60 \mathrm{~mm}$ ) (Fig. 1).

The perirectal abscess was visualized using a curvilinear array echoendoscope (GF-UCT240; Olympus Medical Systems Co., Tokyo, Japan) with a working channel of $3.7 \mathrm{~mm}$. The abscess was then punctured with a 19-gauge needle (Echotip $^{\circledR}$ ultra; Wilson-Cook Medical Inc., Winston-Salem, NC, USA) through the rectal wall after using color Doppler examination to avoid interposed vascular structures (Fig. 2). After the stylet was removed, fluid was aspirated and sent for Gram staining and culture. A 0.035-inch guidewire was then passed through the 19-gauge needle and coiled into the abscess cavity. The tract between the rectum and abscess cavity was dilated using one of two methods: graded dilation or introduction of a $6 \mathrm{~F}$ cystotome. In two patients, a $4.5 \mathrm{~F}$ taper cannula (Olympus Medical Systems Co., Tokyo, Japan) was passed over the guidewire to dilate the tract. The tract was further dilated by using a catheter (Oasis ${ }^{\circledR}$ One Action Stent Introduction System; Cook Ireland Ltd., Limerick, Ireland), followed by an 8-mm Hurricane balloon (Boston Scientific, Marlborough, MA, USA). In the remaining two patients, a 6 F cystotome (Endo-Flex, Voerde, Germany) was passed over the guidewire to dilate the tract. An additional guidewire was placed using a Haber ramp catheter (Wilson-Cook Medical Inc., Winston-Salem, NC, USA), followed by the placement of one or two $7 \mathrm{~F}$ double pigtail plastic stents (Cook Ireland Ltd., Limerick, Ireland) (Figs. 3, 4).

The procedure was performed without any complications in all four patients. All patients experienced immediate relief of symptoms after abscess drainage. The fluid aspirate was purulent in all patients. A follow-up CT scan was obtained 7-14 days after the procedure to assess the response to treatment. All patients showed complete resolution of the abscess 


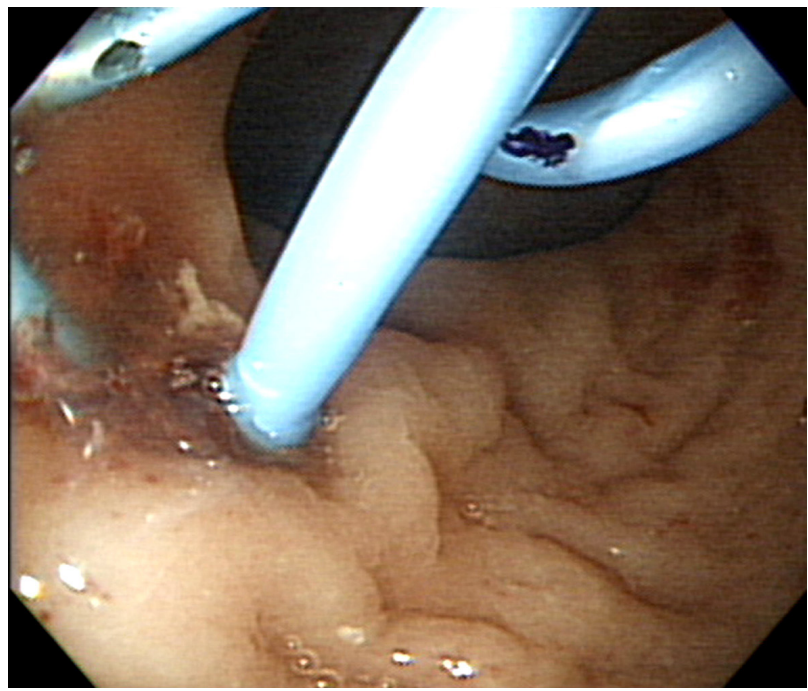

Fig. 3. Endoscopic image of two double pigtail plastic stents in the rectum.

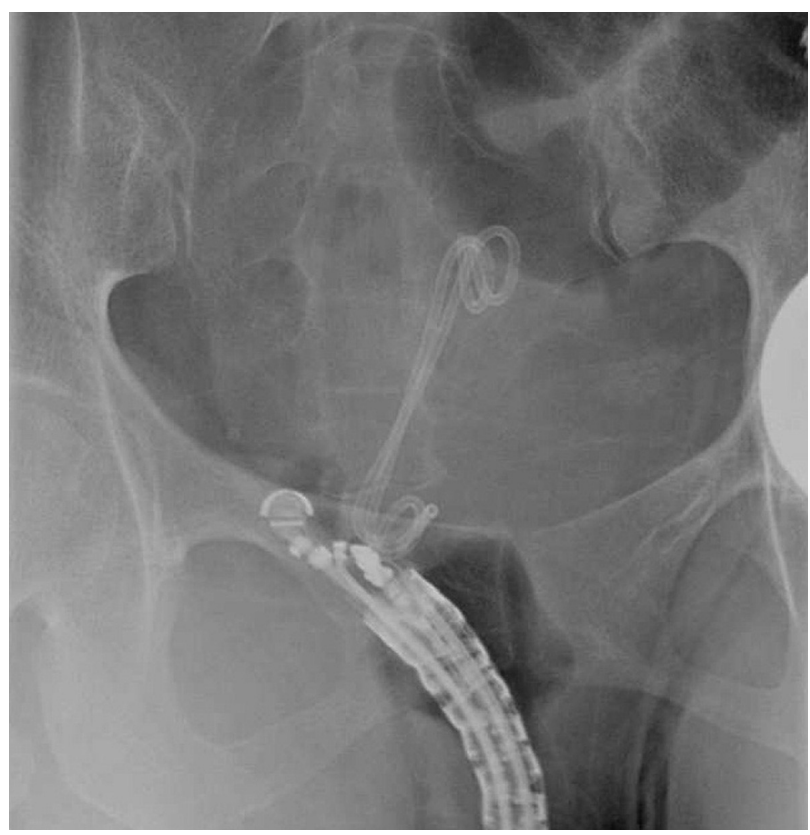

Fig. 4. Fluoroscopic image showing the echoendoscope and two double pigtail stents that were placed in the abscess cavity.

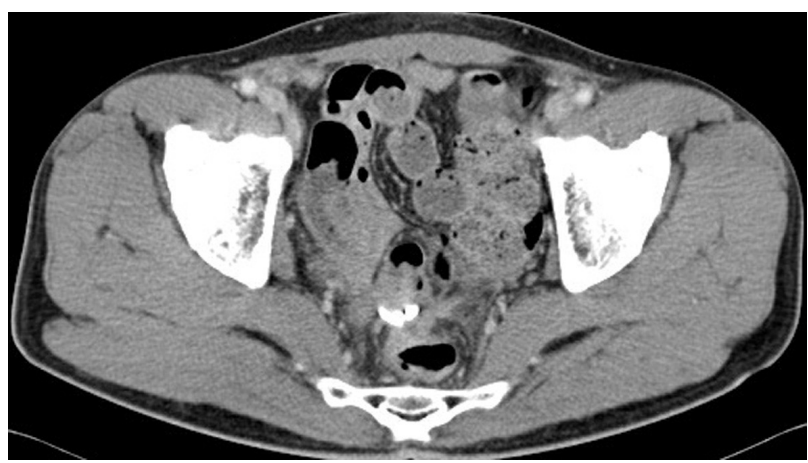

Fig. 5. Follow-up computed tomography (CT) image showing complete resolution of the abscess with the stents. at the time of the follow-up CT scan (Fig. 5). The stents were retrieved successfully via outpatient sigmoidoscopy. The transrectal stents remained in place without migration in all patients. At a median follow-up of 22 months (range, 5-48 months), all four of the patients were clinically well, without any evidence of abscess recurrence.

\section{DISCUSSION}

A pelvic abscess occurs as a postoperative complication of colorectal or gynecologic surgery or secondary to various medical conditions such as inflammatory bowel disease, appendicitis, diverticulitis, ischemic colitis, and pelvic inflammatory disease. ${ }^{1}$ Abscesses deep in the pelvis often pose a clinical challenge because they are surrounded by many organs such as the bladder, prostate, uterus, vagina, bowel, pelvic bone, and neurovascular structures, which hinder the safe routes for percutaneous drainage. Historically, pelvic abscesses have been managed by surgery via the transrectal or transvaginal route under US guidance or via the percutaneous route under CT guidance. ${ }^{6-8}$ However, conventional US-guided or CT-guided drainage only permits the placement of a catheter instead of a stent, which is inconvenient for patients. EUS is being increasingly used as a therapeutic intervention for clinical scenarios including the drainage of peripancreatic fluid collections, biliary and pancreatic duct obstruction, ablation of cystic neoplasms, and radiofrequency ablation of pancreatic malignancies. The EUS-guided technique for drainage is a safer, simpler, and more attractive procedure than surgical or percutaneous drainage because it has a minimal risk of injury to intervening vessels and minimal risk of leakage at the puncture site. In addition, it is feasible for internal stent deployment, which is more comfortable for patients. However, these benefits of EUS in the management of perirectal abscess are not well known to surgeons. If the abscess is located within the reach of the echoendoscope and is not multiloculated, it can be successfully drained using EUS-guided procedures regardless of its cause. ${ }^{9}$

In this case series, we demonstrated that EUS-guided placement of one or two $7 \mathrm{~F}$ stents for the drainage of perirectal abscesses is safe and has excellent clinical outcomes. It should be noted that we did not place any additional drainage catheters. There have been concerns that transrectal stents can clog easily, particularly because of feces or pus. ${ }^{3-5}$ To overcome this, some studies have recommended placing a drainage catheter in order to irrigate the abscess cavity. ${ }^{3-5}$ However, the drainage catheter is an inconvenience for patients. There are two main considerations in solving this problem. First, it is important to understand that the resistance of flow is proportional to the 
length of the route and inversely proportional to the width of the hole. If a long drainage catheter is used, the resistance will be higher than if a short stent is used. The drainage catheter used in these catheter irrigation studies was a $10 \mathrm{~F} 80-\mathrm{cm}$ catheter. Second, intra-abdominal pressure sufficient to empty the rectum with defecation should also empty the abscess cavity rather than promote its filling. ${ }^{10}$ Considering these facts and the results of the present case series as well as similar previous reports, a drainage catheter does not seem to be essential for the management of a perirectal abscess. ${ }^{11}$ The real role of a drainage catheter would be irrigation rather than drainage itself. Therefore, if an abscess is thick with sediments, irrigation during an EUS-guided procedure should be sufficient. Thus far, there are no guidelines for the period for which a stent should be left in place after EUS-guided pelvic abscess drainage, but it may be shorter than the periods for other sites of drainage because of the unique anatomy and physiology of the pelvic cavity that aid abscess emptying. Many authors confirmed the resolution of abscess within 2 weeks and then retrieved the stents. ${ }^{3,5,12}$

There are two limitations in this case series. The number of patients studied was small, and no comparative group managed by an alternative method was available. Despite the small number of patients, our case series found that EUS-guided transrectal stent placement without a drainage catheter was a technically easier, more feasible, and more convenient method than the traditional US- or CT-guided procedure. Prospective multicenter trials are required to validate the technical efficacy and safety of EUS-guided stent placement without a drainage catheter.
Conflicts of Interest

The authors have no financial conflicts of interest.

\section{REFERENCES}

1. Lareau SM, Beigi RH. Pelvic inflammatory disease and tubo-ovarian abscess. Infect Dis Clin North Am 2008;22:693-708, vii.

2. Giovannini M, Bories E, Moutardier V, et al. Drainage of deep pelvic abscesses using therapeutic echo endoscopy. Endoscopy 2003;35:511-514.

3. Trevino JM, Drelichman ER, Varadarajulu S. Modified technique for EUS-guided drainage of pelvic abscess (with video). Gastrointest Endosc 2008;68:1215-1219.

4. Varadarajulu S, Drelichman ER. EUS-guided drainage of pelvic abscess (with video). Gastrointest Endosc 2007;66:372-376.

5. Varadarajulu S, Drelichman ER. Effectiveness of EUS in drainage of pelvic abscesses in 25 consecutive patients (with video). Gastrointest Endosc 2009;70:1121-1127.

6. Benigno BB. Medical and surgical management of the pelvic abscess. Clin Obstet Gynecol 1981;24:1187-1197.

7. Sudakoff GS, Lundeen SJ, Otterson MF. Transrectal and transvaginal sonographic intervention of infected pelvic fluid collections: a complete approach. Ultrasound Q 2005;21:175-185.

8. Jaffe TA, Nelson RC, Delong DM, Paulson EK. Practice patterns in percutaneous image-guided intraabdominal abscess drainage: survey of academic and private practice centers. Radiology 2004;233:750-756.

9. Varadarajulu S, Lee YT. EUS 2008 working group document: evaluation of EUS-guided drainage of pelvic-fluid collections (with video). Gastrointest Endosc 2009;69(Suppl 2):S32-S36.

10. Finne CO 3rd. Transrectal drainage of pelvic abscesses. Dis Colon Rectum 1980;23:293-297.

11. Hadithi M, Bruno MJ. Endoscopic ultrasound-guided drainage of pelvic abscess: a case series of 8 patients. World J Gastrointest Endosc 2014;6:373-378

12. Puri R, Eloubeidi MA, Sud R, Kumar M, Jain P. Endoscopic ultrasound-guided drainage of pelvic abscess without fluoroscopy guidance. J Gastroenterol Hepatol 2010;25:1416-1419. 